\title{
EDUCAÇÃO HUMANIZADA: O SABER E O FAZER DE CADA UM COMPARTILHADO POR TODOS NA ARTE DE EDUCAR
}

\author{
HUMANIZED EDUCATION: THE KNOWLEDGE AND DOING EACH ONE \\ COMPATIBLE BY ALL IN THE ART OF EDUCATION
}

\author{
EDUCACIÓN HUMANIZADA: EL SABER Y EL HACER DE CADA UN \\ COMPATILHADO POR TODOS EN EL ARTE DE EDUCAR
}

\author{
Bruno Freitas ${ }^{1}$
}

\begin{abstract}
RESUMO
Este artigo tem como objetivo refletir sobre a relevância de uma educação humanizada como contribuidora para uma educação mais integradora. Sendo embasada através do posicionamento de diferentes autores, que abordam essa temática tais como Jares (2002), Barros (2007), Freire (2005). Para essa pesquisa usamos como metodologia a pesquisa bibliográfica, que serviu como base para nortear e desenvolver as ideias do trabalho. Os resultados dessa pesquisa têm como finalidade o aprofundamento dos requisitos básicos da educação, na qual seria interessante, que possuísse duas importantes características, seja ela mais integradora e humanizadora, contribuindo para a efetiva formação do indivíduo, no campo cientifico e humano. Conclui-se, que esse artigo apontou fatos importantes, que nos revelam o quanto a nossa educação, tem sido defasada no requisito humanização, sendo necessária ações e intervenções em prol de uma educação muito mais ampla.
\end{abstract}

PALAVRAS-CHAVE: Desenvolvimento. Educação. Humanização.

\section{ABSTRACT}

This article aims to reflect on the relevance of a humanized education as a contributor to a more inclusive education. It is based on the positioning of different authors, who approach this subject such as Jares (2002), Barros (2007), Freire (2005). For this research we used as a methodology the bibliographic research, which served as a basis to guide and develop the ideas of the work. The results of this research aim at deepening the basic requirements of education, in which it would be interesting to have two important characteristics, be it more inclusive and humanizing, contributing to the effective formation of the individual in the scientific and human field. It is concluded that this article pointed to important facts, which reveal to us how much our education has been lagged in the humanization requirement, and actions and interventions for a much broader education are necessary.

KEYWORDS: Development. Education. Humanization.

\section{RESUMEN}

Este artículo tiene como objetivo reflexionar sobre la relevancia de una educación humanizada como contribuyente a una educación más integradora. En el caso de las mujeres, se trata de una de las más importantes de la historia. Para esa investigación usamos como metodología la investigación bibliográfica, que sirvió como base para orientar y desarrollar las ideas del trabajo. Los resultados de esta investigación tienen como finalidad la profundización de los requisitos básicos de la educación, en la cual

\footnotetext{
${ }^{1}$ Anne Sullivan University.
} 


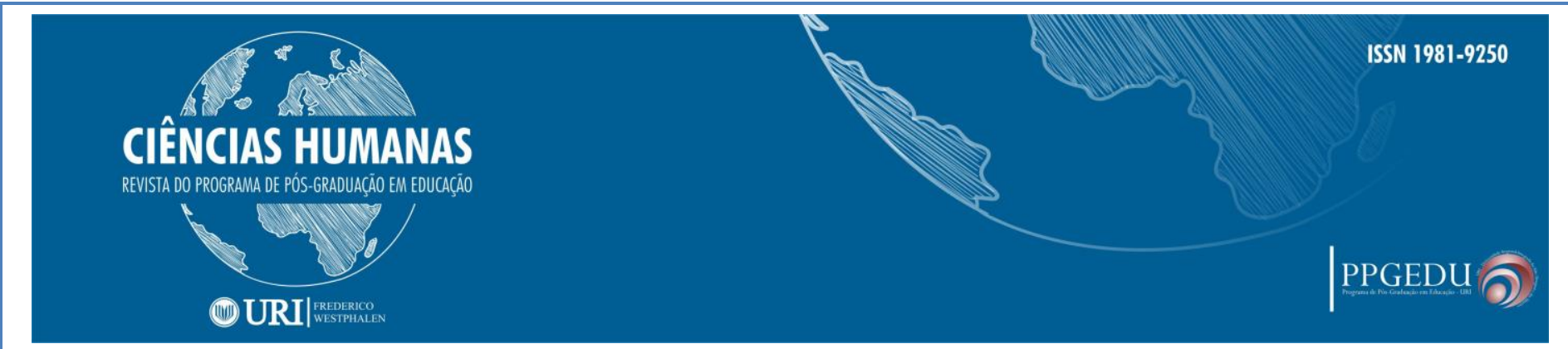

sería interesante, que poseía dos importantes características, ya sea más integradora y humanizadora, contribuyendo a la efectiva formación del individuo, en el campo científico y humano. Se concluye que este artículo apuntó hechos importantes, que nos revelan cuánto nuestra educación, ha sido desfasada en el requisito humanización, siendo necesarias acciones e intervenciones en pro de una educación mucho más amplia.

PALABRAS CLAVE: Desarrollo. Educación. Humanización.

\section{INTRODUÇÃO}

Debater essa temática aqui intitulada de educação humanizada é uma necessidade básica, porque ela se constrói a partir do saber e do fazer de todos, compartilhados em prol de um objetivo comum: Humanização do sujeito. Dessa forma serão alcançados os avanços qualitativos no sistema educacional, tais como o maior desenvolvimento cognitivo, físico, social e emocional do sujeito, onde na maioria das vezes, não é trabalhado da forma que deveria.

Na realidade construir uma educação de fato humanizada é um desafio em meio a tantos problemas educacionais, sociais, culturais e políticos, que afeta direta e indiretamente a qualidade do ensino brasileiro, tornando-o deficiente. Nesse sentido, educar de formal humanizadora o sujeito significa, trabalhar competências e habilidades de forma mais ampla e concreta, onde na maioria das vezes, tem sido trabalhada superficialmente. Para isso, se requer um minucioso trabalho de intervenções, dentro das mais diversas realidades, que temos dentro do sistema educacional.

Alicerçado nisso, o problema desse artigo consiste na análise, que a ausência de uma educação humanizadora, traz alguns retrocessos no processo de formação educacional do sujeito, a exemplo a desumanização do sujeito, que contribui para o desamor, para violência e a insensibilidade. A base teórica usada é o posicionamento de alguns autores, que trazem essa importante discussão como Jares (2002), Barros (2007), Freire (2005) e outros.A metodologia aqui aplicada é a pesquisa bibliografica, que consiste na busa de diferentes pontos de vista, com autores divergentes e convergentes

Os desafios da educação na atualidade são inúmeros e um deles é alcançar uma excelência educacional, uma educação mais ampla e mais concreta, que contemple o sujeito por completo, tornando-o muito mais apto para os desafios da vida, formando as

\begin{tabular}{l|l} 
Recebido em: 29/08/2018 & Aceito em: 10/10/2018
\end{tabular}




\section{CIÊNCIAS HUMANAS}

REVISTA DO PROGRAMA DE PÓS-GRADUAĞ̈O EM EDUCAĞ̄o

\section{(1) URI|}

aptidões emocionais, físicas e sociais, que lhes são de direito dentro do processo educativo.

$\mathrm{O}$ artigo se encontra organizado em quatro capítulos, sendo que o primeiro realiza uma pequena síntese sobre os conceitos, de o que é uma educação humanizada? O segundo capítulo expõe a necessidade da humanização do sujeito dentro do contexto educacional, em prol de uma educação muito mais integradora e humana; O terceiro capítulo traz uma abordagem sobre o ensinar e o aprender humanamente, apontado o posicionamento de alguns teóricos; $\mathrm{O}$ quarto capítulo mostra o processo de desumanização do sujeito, um grave problema na atualidade, e que requer uma ação de intervenção.

A educação é um processo contínuo de construção e reconstrução, e é imprescindível que haja as condições básicas e, com o auxilio necessário dos recursos humanos, financeiros e pedagógicos, para que tenha o alicerce base construído. Para que assim, esse tipo de educação se consolide.

Dentro desse grande desafio de uma educação humanizada o objetivo aqui é refletir sobre a relevância de uma educação humanizada como contribuidora para uma educação mais integradora, que se faz tão necessária em nossa sociedade contemporânea, buscando conhecer e aplicar as estratégias corretas dentro da prática docente, servindo de amenização para os problemas educacionais, tornando a educação muito mais integradora.

Partindo para os objetivos, que aqui se almeja alcançar o estudo tem um caráter bibliografico, pois usam de forma interdisciplinar diferentes aspectos, apontados pelos autores, que expõe seus posicionamentos. Como recursos aplicados foram utilizados o levantamento bibliográfico, dando fundamentação para a temática em pauta, sendo a justificativa do trabalho é o interesse incansável pelo conhecimento, que permita construir dia a dia uma educação mais humanizadora, permitindo uma melhor formação humana, social e cientifica do sujeito dentro do processo de escolarização. Com base nisso surge a importância desse trabalho para o universo escolar. 


\section{CIÊNCIAS HUMANAS}

REVISTA DO PROGRAMA DE PÓS-GRADUAĞ̈O EM EDUCAĞ̄o

\section{(10) URI|}

\section{MATERIAL E MÉTODO}

Martins (2004), diz que a metodologia é como um instrumento a serviço da pesquisa, que indagará limites e possibilidades dos caminhos do processo científico. Nesse sentido Chizzotti (2010), afirma que a pesquisa é um esforço constante de observações, reflexões, análises e sínteses na busca de informações, que procuram descobrir a lógica e a coerência de um determinado assunto em pauta, nesse caso em especifico à educação humanizada. Então, o tipo de pesquisa adotada nesse trabalho foi à pesquisa bibliográfica com o objetivo de detalhar os pontos mais pertinentes, que melhor descrevem essa temática. As fontes usadas na pesquisa seguem duas linhas a primária, onde foi investigado conceitos e referencias sobre a temática e fontes secundárias.

O método usado para a elaboração da pesquisa é o bibliográfico, na qual tem como principal característica "explorar por meio de diferentes autores a essência de um determinado assunto" (LAKATOS, 2007, p 107). Permitindo que fosse construído passo a passo o referencial teórico desse trabalho. A aplicação dessa pesquisa funcionou como uma revisão de literatura, onde foram lidos e pesquisados pontos chaves sobre essa importante discussão.

\section{REFERENCIAL TEÓRICO: DESTRINCHANDO A TEMÁTICA}

A educação humanizada tem sido um tema relevante no cenário educacional, sendo assim uma necessidade para uma melhor formação do sujeito, uma vez que o mesmo vem sofrendo um rápido processo de desumanização. Nesse sentido Cortella (2001) explica que o educador mais uma vez, tem o grande desafio de procurar estratégias, que possibilitem uma educação com o perfil de mais humanizadora. No sentido de propiciar um ensino superador, no sentido de amenizar em partes as desigualdades sociais e culturais, que tem sido hoje um obstáculo, no que se refere a um ensino mais equalizador e humanista.

Uma educação para ser de fato humanizadora e humanizada deve atender seis aspectos de grande relevância. O primeiro deles é o altruísmo. Um componente 


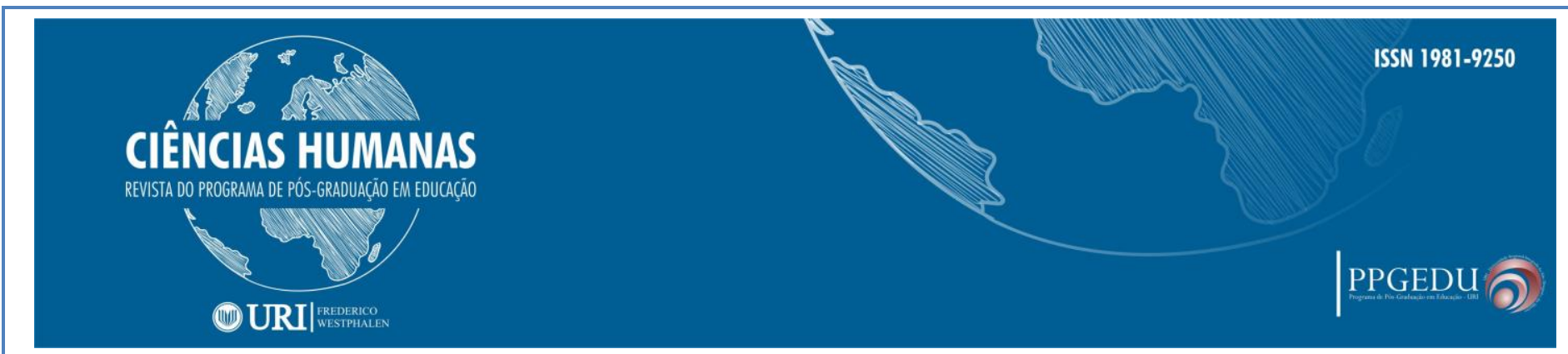

necessário para uma educação mais humanizadora. De acordo com o dicionário Aurélio (2002) o altruísmo é compreendido como a capacidade de tentar fazer, que todos participem. Por outro lado, ainda existe muito a ser estudado dentro dessa importante área, muitos questionamento surgem, tais como: O que significa isso? A definição de altruísmo dada por Haldane (1932) é a união e o trabalho coletivo. Exemplificado com o comportamento altruísta das abelhas para uma melhor compreensão, que atacam os invasores da colmeia com o próprio ferrão, mesmo sabendo que agindo dessa forma, morreram. E com esse modelo de vida e comportamento das abelhas aprendemos lições riquíssimas, que podem ser contextualizadas com a educação em vários aspectos. Todas as operárias produzem o precioso mel, nós enquanto educadores devemos produzir aprendizagem, e aprendizagem essas que sejam sempre significativas.

Outro exemplo de comportamento altruísta é apontando por Darwin (1985) ao exemplificar com a vida social e instintiva dos macacos, que avisam seus parceiros quando avistam um leopardo, arriscando a própria vida. Trazendo para o contexto educacional, isso quer dizer que a educação humanizadora é aquela que está alicerçada no afeto, nos vínculos de amizade e no respeito e na conservação á vida do outro. Ainda, dentro da temática altruísmo na educação um terceiro exemplo é apontado por Hauser (1996), ao falar sobre os morcegos-vampiros, que compartilham o sangue obtido com os membros de seu grupo (WILKINSON,1990).Transcrevendo para a educação, educar nada mais é do que compartilhar experiências e conhecimentos.Enriquecendo a construção do sujeito como um ser muito mais humano,do que ele já é.

O segundo aspecto que é necessário para a educação humanizadora é a resiliência.Que de acordo com o dicionário Aurelio (2002) é a capacidade que o indivíduo desenvolve mesmo em tempos de crise.A palavra resiliencia vem do latim "resilo" e se refere à capacidade de retornar ao estado anterior. Esse importante conceito foi usado inicialmente nas áreas das ciências exatas. E ao contextualizar com a educação, tem um grande significado. Porque educar na atualidade, representa uma árdua batalha dia após dia, de formar sujeitos em pessoas transformadoras e ativos da sua realidade, mesmo reconhecendo que a sociedade e a família se encontram desestruturadas e com alguns conceitos destorcidos em muitas áreas.E cabe o educador 


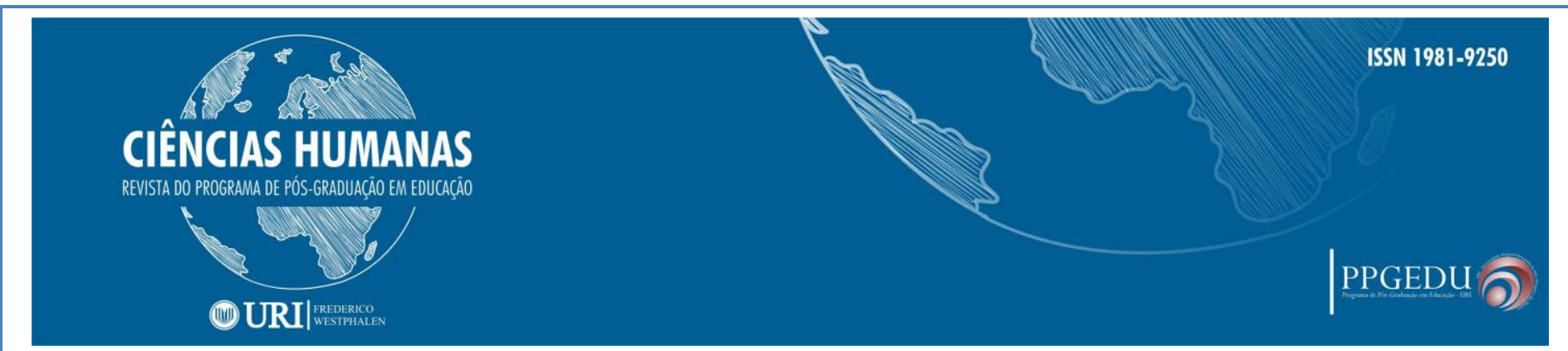

assumir o importante papel de resiliente, trabalhando em cima dessas deficiências, que são inúmeras nos mais diversos aspectos. Analisando o pensamento de Barlach, Limongi-França \& Malvezzi (2008) uma educação com resiliência, significa também à capacidade elástica de um corpo físico. Em outras palavras educação deve apresentar essa elasticidade, ou seja, essa flexibilidade. Isso quer dizer, que educar é moldar o sujeito dentro de padrões éticos e morais.

O termo resiliência é debatido também por Souza \& Cerveny (2006), definindo como um conjunto de traços de personalidade, capacidades ou habilidades que tornam as pessoas resistentes. Essas palavras descrevem com perfeição o sentido real da educação. Constituir homens e mulheres com sua personalidade for e que possuam capacidades e habilidades bem desenvolvidas.Esse desafio requer, um conjunto específico de ações e intervenções, para que tais objetivos sejam de fato contemplados.

Diante de Souza \& Cerveny (2006), acrescenta que o desenvolvimento da resiliência educacional, permite formar um sujeito menos vulnerável as muitas situações da vida cotidiana e automaticamente um sujeito mais saudável, tanto sentido físico como espiritual e intelectual.

Os autores Souza \& Cerveny (2006) discutem também a importância de formar uma sociedade mais firme e resistente. Usando as palavras dos mesmos autores diz que indivíduos resilientes, possuem um perfil de vencedores, que conseguem driblar as situações problemas, que são muitos mais ágeis para a resolução de problemas, dentro da vida prática. Isso nos faz recordar, que o papel da escola não é o de apenas preparar o sujeito para vestibulares e exames. É necessário preparar para a vida e seus muitos desafios, tornado-os vencedores em meio as adversidades.

A educação como um todo, deve priorizar o desenvolvimento da resiliência como uma etapa indispensável para a construção de uma aprendizagem mais significativa, e menos mecânica. O ensino deve propiciar a resiliência, pois aqui é compreendida como um fenômeno dinâmico, que deve acontecer por meio da interação, que são estabelecidas através do meio social e educacional.

Por último Cimbalista (2007), diz que a resiliência tem o poder de provocar a transformação, e isso que a educação também faz transformar o sujeito de forma 


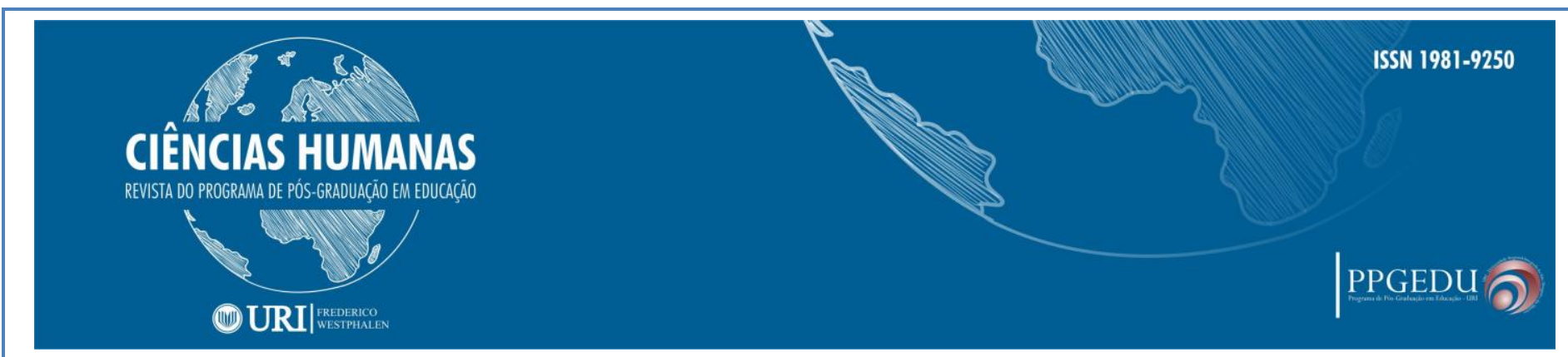

positiva como agente transformador da realidade, em que ele está inserido. Daí, surge à necessidade de unificar educação e resiliência como dois pontos indissociáveis dentro desse processo educativo.

A educação humanizada deve atentar também para o terceiro aspecto que consiste na coragem. Que nas palavras de Madalena Freire (2008), diz que o medo e a coragem são dois termos presentes na educação. E na atualidade educar, se resume em um ato de coragem, em meio a tantas adversidades e situações desafiadoras, que acontecem dentro do ambiente escolar. Com por exemplo, o grande índice de violência nas escolas, sejam elas as verbais, psicológicas ou até mesmo físicas. Como confirma Pedro Silva (2004), afirma que a principal causa, que gera a chamada violência escolar é a falta de afeto, valores e modelos positivos sociais. Então, é necessário articular ações educativas e sociais para amenizar, a triste realidade de muitos dos nossos alunos que vivem em lares, onde são vitimas da violência e ao mesmo tempo protagonistas da mesma. Dessa forma é necessário exercitar na prática docente a fala de Mangini (2008), no qual aponta que o caminho a ser trilhado é o da afetividade e da socialização. Ainda, de acordo com Madalena Freire (2008) a coragem educacional tem o papel de buscar a alegria, a esperança, a liberdade de uma sociedade. Isso nos faz lembrar da educação de valores e princípios, que é tão necessária para uma melhor formação do sujeito, e que é iniciada no seio familiar.

Seguidamente na construção de uma educação mais humanizadora, temos o quarto aspecto denominado de proatividade. Que de acordo com o dicionário Aurélio (2002) consiste na a capacidade de se adiantar e resolver situações antecipadamente, ou seja, resolver situações, antes que se tornem problemas. E a educação deve possuir essa característica básica de resolver problemas, e nunca se fazer de cega para tais situações que estão tão presentes em todo o contexto escolar.Como,por exemplo em pesquisa recente do INEP ( 2016 ) um dos maiores problemas da educação brasileira é a evasão escolar,pois metade dos jovens entre 15 e 17 anos não estão matriculada no ensino médio. E a mesma pesquisa mostra que a proporção dos que abandonaram a escola nessa etapa saltou de 7,2\% para 16,2\% em 12 anos.Tais números são preocupantes, mostrando que a educação não tem sido afetuosa, nem calorosa.Então, a educação para 


\section{CIÊNCIAS HUMANAS}

REVISTA DO PROGRAMA DE PÓS-GRADUAĞ̈O EM EDUCAĞ̄o

\section{(1) URI|}

ser de fato proativa deve permitir situações saudáveis de disputas, onde todos os personagens do processo educativo, articulem soluções para os problemas educacionais, traçando caminhos que conduzam ao sucesso escolar,que nesse caso são as políticas públicas educacionais,como parte da solução.

Para Fernandez (2001) "proatividade" é um elemento chave que permite compor uma educação de perfil muito mais significativa e afetiva.Isso significa, que a proatividade faz menção a educação afetiva e emocional do sujeito, sendo que ambas são necessárias para a educação se tornar mais e mais humanizadora.

Gonçalves (2015) em uma das suas obras intituladas de Postura Proativa, diz que a educação tem o poder de mudar o sujeito, a sociedade dando um direcionamento positivo para uma sociedade cada vez mais afetiva e efetiva.O autor conclui sua fala falando da necessidade de profissionais proativos.Nesse sentido o educador proativo é aquele que possui e as atitudes, ações de prontidão e urgência para solucionar ou amenizar os entraves da educação na atualidade, em meio a tantas complexidades.

E, seguindo a linha dos componentes necessário para a educação humanizada deve atentar para o quinto aspecto, aqui chamando de afeto. A questão da afetividade é um ponto chave para todo e qualquer relacionamento. A educação nada mais é do que uma importante construção de relacionamentos e de relações que são vivenciadas dia a dia. Nesse sentido Fernández (1991), explica que a aprendizagem deve ser repleta de afetividade. E ser afetuoso é mais do que necessário, já que nossa sociedade atual, vem sofrendo com um grande desamor nas mais diversas situações. Para melhor compreensão a afetividade é um processo de construção e reconstrução, que acontece dentro das interações e relações sociais. Isso significa, que não se constitui uma educação humanizadora, sem a presença da afetividade, que deve ser cultivada e trabalhada dia a dia.

Ainda dentro da temática afetividade educacional os Parâmetros Curriculares Nacionais (1997) diz que a educação deve ser capaz de compreender atitudes, solidariedade, cooperação e respeito. Todos esses importantes sentimentos estão intimamente relacionados com o afeto. Observando ainda, os PCN (1997) é trazida a reflexão de que é primordial desenvolver o sentimentos de confiança sobre as 


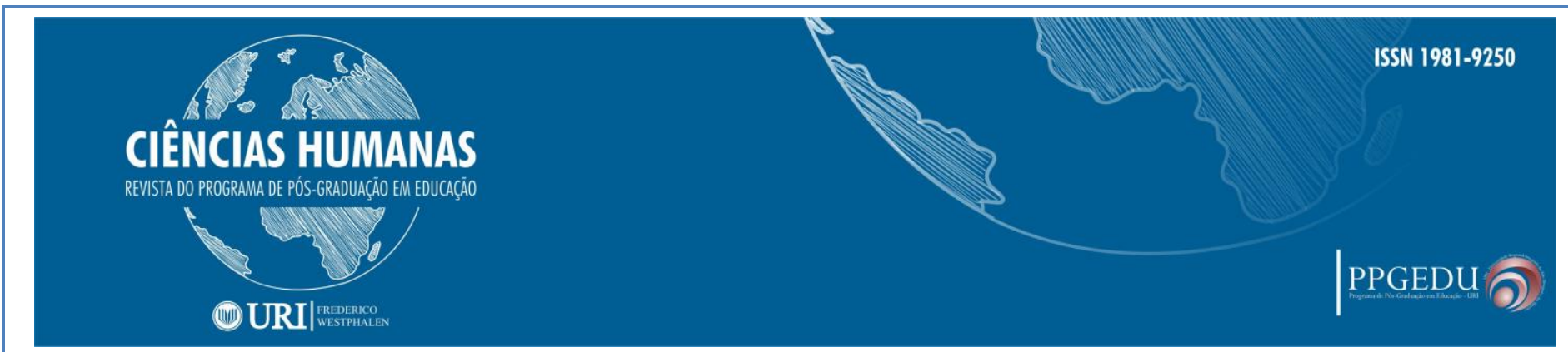

capacidades afetiva, física, cognitiva, ética do sujeito. Isso é algo desafiador, mais deve ser priorizado na construção de um sujeito cada vez mais humano e afetuoso, para consigo mesmo e para com o outro.

A afetividade é tema de debate para Comenius (2002), que explica que a criança desde muito cedo, deve receber ações afetuosas do grupo familiar e seguidamente do grupo escolar, para que o mesmo seja, capaz de receber todas as imagens e informações, que estão sendo ensinadas. $\mathrm{O}$ autor finaliza sua fala dizendo, que o cérebro do homem, e torna mais sólido e duradouro quando a aprendizagem é absorvida sob o vínculo da afetividade.

Comenius (2002) diz em seus estudos que a falta de afetividade por parte do grupo familiar pode resultar na formação de monstros humanos. E lamentavelmente isso tem sido muito comum na sociedade contemporânea. Daí, surge em caráter emergencial que sejam inseridos e trabalhos as questões sócio afetivo e humanas, com o objetivo maior de evitar que novos monstros humanos se constituem e sirvam de ameaças para outras pessoas.

O ser humano tem uma necessidade de amar e de ser amado. E, isso é papel inicial da base familiar como confirma os estudos de Cury (2007) ao se expressar dizendo, que os filhos não precisam de pais gigantes, mas de seres humanos que falem a sua linguagem e sejam capazes de penetrar-lhes o coração. Essas palavras demonstram com perfeição o papel familiar a ser cumprido com a criação e a formação do sujeito. A importância da família é inquestionável, infelizmente ainda, existem muitas famílias que não reconhecem, nem fazem valer essa importante função. Cury (2007) é também conhecido por trabalhos, que valorizam as questões sócio emocionais. O autor ainda, define a família como o berço do amor, da compreensão, do afeto.

Ainda dentro da temática afetividade Guimarães (2008) diz, que o amor familiar ou escolar não é aquele só com palavras, mas sim de atos, açoes e atitudes. Isso quer dizer que educação familiar ou escolar, nada mais é do que um ato de amor e de inúmeros sacrifícios, que são realizados todos os dias. Daí, surge a importância, que cada educador exerça o dom da afetividade dentro de sua ação docente, pois é por meio dele e através, dele que conseguiremos humanizar cada vez mais o sujeito. 


\section{CIÊNCIAS HUMANAS}

REVISTA DO PROGRAMA DE PÓS-GRADUAĞ̈O EM EDUCAĞ̄o

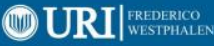

A escola é uma segunda casa, como já estamos acostumados a ouvir e toda casa deve apresentar um perfil caloroso e afetuoso, pois não só criança como todos nós adolecentes, jovens e adultos precisamos de atenção, afeto e carinho.O que é preciso saber sobre a educação humanizada? A palavra humanizada faz referência a humanidade e humanidade faz ligação com amor e com o sentimento de pertencimento. Entao, teoricamente a educação humanizada é uma abordagem que envolve o emocional/afetiva, estabelecida pela parceria entre escola e família.

E, é isso que cada educador deve inserir dentro de sua ação pedagógica, amor, disciplina e a valorização do sentimento de pertencimento e do respeito mútuo.

É desafio da família e da escola, enquanto instituição exercitar e estimular a humanidade, que cada sujeito tem dentro de si. Como confirma Saviani (2000) ao explicar, que o homem não se faz homem naturalmente. Para dominar o pensamento, os sentimentos, o querer, a ação e a avaliação.É necessário o árduo trabalho educativo. Como fazer isso? Isso pode ser feito por meio da criatividade, que nada mais é do que o ato de agir, sentir e pensar, ou seja, são estímulos de comportamento, que cada vez mais necessita ser humanizados e trabalhados, para que venha de dentro para fora do sujeito. E tal criatividade recebe o nome de educação, um processo indispensavel para $\mathrm{o}$ indíviduo.

O sexto e último aspecto é a criatividade. Uma etapa essencial dentro do processo de ensino aprendizagem, como explica o psiquiatra e escritor Maldonato (2006), da Universidade de Basilicatana na Itália, que a criatividade humana tem vínculos com as características de nosso cérebro. Isso significa que a educação humanizadora, precisa de educadores com este importante perfil. Analisando estudos recentes Maldonato (2006) diz que a criatividade trabalha dois hemisférios do cérebro: O primeiro é o lado esquerdo que, está ligado às funções lógico-simbólicas, como as estruturas e funções da linguagem, enquanto o hemisfério direito trabalha com as emoções e a criatividade. Assim, é de tamanha relevância, que os educadores explorem atividades pedagógicas, que estimulem e ampliem o grau de criatividade do sujeito.

A criatividade é objeto de estudos de Sternberg (2003), e o autor vai muito além, ao afirmar que a existência da criatividade é indispensavel para o desenvolvimento 


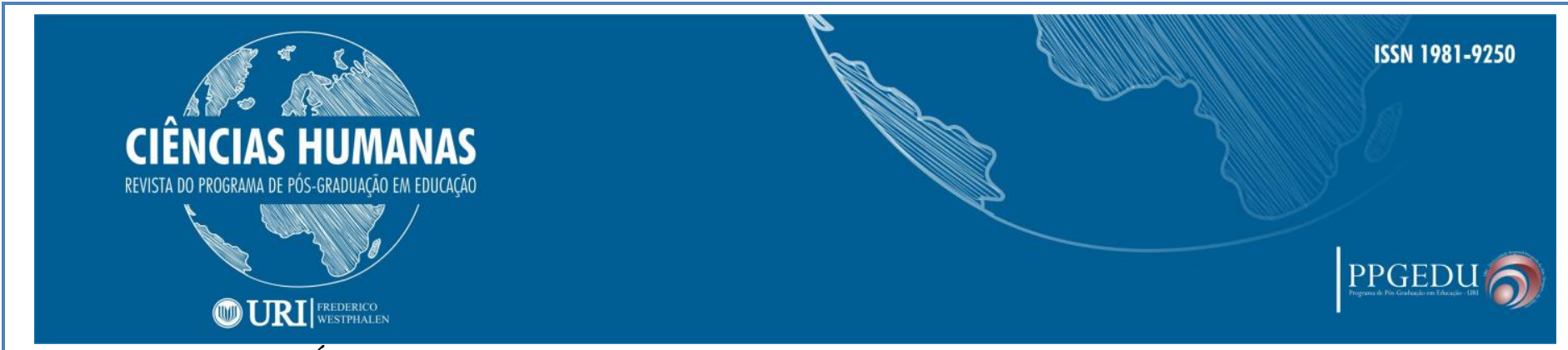

humano. É interessante que, o termo criatividde funciona em concordância com outros seis recursos distintos, necessário para o suceso do processo de ensino aprensizagem, principalmente se tratando de educacao humanizadora.São eles: Habilidades intelectuais, conhecimento, estilos de pensamento, personalidade, motivação e ambiente adequado. Dessa forma a criatividade requer um exercicio contínuo em combinação com esses fatores aqui citados.

A educação como um todo precisa criar momentos propícios para criar hábitos saudáveis, como por exemplo, olhar para o outro com um sentimento fraterno, de amizade,de solidariedade.Sentimentos esses que são relevantes,e que a escola, a sociedade, a família como um todo tem deixado passar despercebido, ou não tem valorizado da forma correta.

\section{A HUMANIZAÇÃO DO SER}

Ao falar de humanizar mais e mais o sujeito, logo recorremos à família e em segundo plano a escola. Para de fato humanizar o sujeito de forma mais ampla é necessário, que cada educador no uso de suas funções possua em seu perfil a chamada humana docência? O que seria a humana docência? Para essa importante resposta é necessário recorrer aos estudos de Arroyo (2000) que em uma das suas obras trata, com especificidade sobre a humana docência. Arroyo (2000) ressalta que é importante trabalhar a humanização do sujeito, em todas as suas instâncias. E, que a visão desse educador deve ser muito ampla enxergando, além daquilo que os olhos podem nos mostrar. $\mathrm{O}$ educador humanizador é aquele que enxerga o aluno sob os olhos da afetividade, da amizade, do carinho e principalmente com os olhos do amor.

Nesse sentido a escola deve está apta, não só para transmitir conceitos científicos, teorias e fórmulas.E, sim preparar o individuo dentro de um requisito tão básico, que é a humanização do ser. É ai, que surge a necessidade, que ação docente seja alicerçada nisso.

Arroyo (2000) faz uma reflexão, no que se refere à qualidade dos profissionais da educação, que estão atuando dia a dia .É vital que esse educador inove, enfrente 


\section{CIÊNCIAS HUMANAS}

REVISTA DO PROGRAMA DE PÓS-GRADUAĞ̈O EM EDUCAĞ̄o

\section{(1) URI|}

desafios, busque novos horizontes, novas estratégias e metodologias para que de fato seja, consolidada uma aprendizagem de fato humanizadora.

Ao falar de educação humanização Freire (2005), diz que ensinar e aprender são dois processos, que acontecem de forma simultânea. Então, é preciso articular e trabalhar maneiras diferentes, objetivando métodos que consolidem um ensinar e um aprender humanamente.Nesse sentido, cada educador no uso de suas funções deve exercer o ato de educar sob a ótica da humanidade, com o intuito cada vez mais tornarse humano e humanizador frente a educação.

A escola deve ser um lugar não só para construção de saberes científicos, mas também o local para o exerciciodo bem estár, do lazer, da alegria e da felicidade o sujeito. E a felicidade é algo, que vão sendo pouco a pouco construído, por meio de um cuidado especial com o sujeito, por meio de atitudes positivas, que sejam estimulantes uns para com os outros.

No livro a Humana Docência de Arroyo (2000) o autor fala sobre nós seres humanos como uma janela e não como um reflexo. Isso significa que o ser humano deve ser trabalhado e enxergado, como uma oportunidade de ser trabalhado e lapidado como ouro bruto, que requer moldagem em todo o seu potencial.

Na educação humanizada é recomendavel, que sejam trabalhados quatro pontos bem distintos, sendo a primeira a consciência instintiva, que de acordo com Vygotski, (2001) é um sistema de transmissores, que adquire a qualidade de sensações secundárias. Como por exemplo, as simples ações de comer, vestir, dormir etc. Esse tipo de consciência é natural a todos os seres humanos, mas o processo educativo também é necessário a ela, pois existem atitudes e ações, por mais simples que seja, requer uma reeducação.

A segunda é a consciência emocional, que consiste no conjunto de diferentes sentimentos que todos nós temos. De acordo com Isquerra (2009) a consciência emocional é o despertar da inteligência emocional, isso significa que trabalhar o sujeito dentro do processo escolar é processo muito complexo, pois envolve o "eu" emocional. Então, cabe a esse educador lidar com as próprias emoções e com as emoções do outro, que em algum momento fluíram dentro das ações e atitudes. 


\section{CIÊNCIAS HUMANAS}

REVISTA DO PROGRAMA DE PÓS-GRADUAĞ̈O EM EDUCAĞ̄o

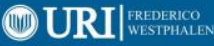

Ainda dentro dessa temática, o próprio Goleman (2003) nos explica em livros como "A Prática da Inteligência Emocional", que as emoções quando são bem desenvolvidas nos auxilia positivamente a resolução e adaptação dos mais diversos problemas e desafios da vida cotidiana. É papel da escola formar um sujeito autônomo e capaz de resolver situações problemas. Então, a educação humanizadora deve abrir espaço, para tratar essa importante questão.

A consciência intelectual é o terceiro ponto dessa discussão. Que está relacionada com o alto conhecimento, que cada pessoa tem a desenvolver. De acordo com Nietzsche (2003) esse tipo de consciência está relacionada como pessoas dotadas ou geniais, ou seja, é a capacidade que temos de aprender, seja em grau normal, moderado ou avançado.

E, por último a consciência espiritual o quarto ponto dessa discussão, que consiste aqui como uma visão entre o eu e o outro. Essa consciência é muito importante no mundo etnocêntrico e egoísta em que nós estamos inseridos. Nesse sentido Jung (1991) diz, que a aquele que olhar para fora sonha, mas aquele que olhar para dentro desperta. Isso significa que a educação deve ter essa visão do outro, compartilhar com o outro, perceber o outro a sua volta. E ao observar a educação na contemporaneidade, falta esses requisitos tão básicos e tão humanos, que tem sido cada vez mais escassos.

A educação é um árduo processo que deve contemplar todas essas importantes especificidades que aqui são chamados de consciências. Assim, sendo a educação humanizada deve ser aquela que forma apenas um mero ser humano pleno com competências e habilidades, mas formar o ser humano com artigo definido "o" que marca uma época, que faz um diferencial, que contribui positivamente para sua sociedade, em que está inserido.

Para Freire (2005) um defensor da educação humanizadora, diz que a educação é um diálogo que serve para instrumentalizar as diferentes formas do saber. Freire (2005) finaliza sua fala afirmando que a educação é um ato criador, um ato crítico. E dentro do ensino humanizador, isso acontece de forma mais ampla.

Dentro desse questionamento Castanho (1989), diz que uma sociedade para se tornar mais humana, é preciso a participação intensa do processo educativo. $\mathrm{O}$ autor 


\section{CIÊNCIAS HUMANAS}

REVISTA DO PROGRAMA DE PÓS-GRADUAĞ̈O EM EDUCAĞ̄o

\section{(1) URI|}

conclui sua fala dizendo que a relação cooperativa e a amizade entre as pessoas são dois elementos imprescindíveis na formação da educação humanizadora.

\section{ENSINAR E APRENDER HUMANAMENTE}

A educação é um processo de troca de saberes e de experiências, ao mesmo tempo, que quem ensina também aprende. E de acordo com Martinez (2009) se aprende a fazer fazendo.Ao falar de aprendizagem é importante ressaltar, que o cérebro humano de acordo com Ramachandran (2014) e estudiosos do Centro para Estudo do Cérebro em San Diego, diz que existe três filtros que trabalha no cérebro, para que venhamos desenvolver algum tipo de aprendizado.

De acordo com Neurociência o cérebro é capaz de processar as informações recebidas, analisá-las. E dentro do processo escolar é importante, que esse educador conheça toda essa trajetória. De acordo com Buzan (2005) as maiores funções do cérebro são: 1- Recepção: $O$ cérebro recebe informação pelos seus sentidos. 2Armazenamento: $\mathrm{O}$ cérebro retém e armazena informação e consegue acessá-la em larga escala. 3- Análise: Seu cérebro reconhece padrões e organiza informações de modo que façam sentido. É importante ressaltar que a percepção, o armazenamento e analise são filtro que passam pelo campo afetivo, daí surge à importância de se priorizar a educação emocional e a educação humanizada. Da qual deve haver uma sintonia em todos os estágios da escolarização.

O sistema radicular que é responsável em dar sentido às coisas. É o que chamamos também do caminho para uma aprendizagem significativa. Então, se resume que aprendizagem significativa é aquele que somos capazes de transportar como útil aquilo que se aprende dentro do ambiente escolar, para a nossa vida prática. E esse processo de transposição é muito difícil e desafiador.

Nesse sentido, surge a importância de trabalhar o ensino de forma contextualizada com a realidade de nossos alunos, e nunca descontextualizado. Oliveira (2008) explica que o cérebro humano produz uma série de processos químicos e elétricos. Isso significa que as informações que ouvimos são captadas por nossos sentidos, em especifico visão e audição, sendo dirigidas para o cérebro.E se tratando 


\section{CIÊNCIAS HUMANAS}

REVISTA DO PROGRAMA DE PÓS-GRADUAĞ̈O EM EDUCAĞ̄o

\section{(1) URI|}

de educação humanizada é de fundamental importância dar sentido as coisas.É o que chamamos também de aprendizagem significativa, aquilo absorvemos como um aprendizado, e que somos capazes de transportar como útil para a nossa vida prática.Nesse sentido surge a importância de trabalhar o ensino sempre de forma contextualizada com a realidade de nossos alunos.

Diante de Freedman \& Engl (2003) apresenta a dopamina (DA) como um neurotransmissor catecolamínico que atua como alvo terapêutico no sistema nervoso central. A dopamina é ainda um importante filtro que é responsável pelo prazer e pela satisfação. Quando o ser humano é estimulado a sentir a sensação de prazer, ele tem maiores possibilidade de aprender muito mais. E dentro da educação humanizadora é importante estimular a dopamina em nossos alunos, propiciando atividades didáticas e lúdicas que sejam capazes de despertar o prazer e a felicidade.

De acordo com a "Declaração Mundial sobre a Educação para Todos", produzido pela UNESCO (1990), que estabelece, em síntese, o seguinte: Educar significa "aprender a conhecer", "aprender a fazer", "aprender a viver junto" e "aprender a ser". Com base nessa explicação as inúmeras duvidas, acerca desses dois verbos, que para muitos tem o mesmo significado são explicadas. Mesmo, assim ainda há muitos pensamentos errôneos por parte de muitos educadores, que ainda tem uma visão pequena ao pensarem que esses dois verbos são totalmente sinônimos.Todavia existe uma grande diferença, entre ambas palavras, na qual aqui foram explicadas.

Ainda falando de ensinar e educar é de fácil percepção compreender um exemplo claro, ao fazer uma viagem na linha do tempo e analisar o sistema tradicional, onde era priorizado apenas o ato de ensinar e transmitir conteúdos. Já, no que se se refere à educação humanizada o que prevalece é o educar, que vai além do ato de transferir conteúdos. Educar é transferir sentimentos é transferir sentido e significado a tudo aquilo que aprendemos.

Assim nos faz lembrar que a educação de acordo com a UNESCO (1990), traz a importância dos 4 pilares da educação:Aprender a conhecer. É quando tornamos prazeroso o ato de compreender, descobrir ou construir o conhecimento. Aprender a 


\section{CIÊNCIAS HUMANAS}

REVISTA DO PROGRAMA DE PÓS-GRADUAĞ̈O EM EDUCAĞ̄o

\section{(1) URI|}

fazer em outras palavras significa ir além do conhecimento teórico e entrar no setor prático.

Aprender a viver com os outros, representa na prática uma vida harmônica e sociável com os demais seres humanos. E por último o aprender a ser que consiste na formação da identidade e na personalidade individual que cada sujeito tem.

\section{O PROCESSO DE DESUMANIZAÇÃO DO SUJEITO}

A escola pública, a sociedade as famílias no geral vem enfrenta esse grave problema aqui intitulada como a desumanização, onde tem impactado o índice de violência nas suas mais diversas facetas. A desumanização do sujeito é dos fatores que gera a violência um problema social que afeta todas as camadas da sociedade, e de acordo com Belon e Ferreira (2012) nos mostra um cenário violento de Bullying nas escolas que causam repulsa, indignação, medo e até horror. É nesse sentindo que a arma mais poderosa para mudar esse triste panorama é a educação humanizada por parte da instituição escolar e também da familiar.

A desumanização é também tema nos estudos de Pereira (2003), onde ela explica o crescimento excessivo da violência física e moral, esgarçamento de laços familiares e afetivos, desarmonia do tecido social, caos urbano, perda de identidade do indivíduo. Tantos problemas que são gerados em parte pela falar de uma educação emocional e integral que contemple a formação moral, ética do sujeito. Com o intuito principal de humanizar mais e mais esse sujeito, essa tem sido uma grande carência dentro do contexto escolar.

Segundo a UNESCO (2004), 50\% do corpo docente de São Paulo já sofreram algum tipo de agressão. Da mesma forma são os alunos que a cada instante são vítimas de algum tipo de violência dentro do espaço escolar, e isso é preocupante e requer uma intervenção.

Infelizmente a violência é um problema de caráter social, e tem se alastrado de uma forma incontrolável, e isso se dá também pela falta de humanização do sujeito a UNESCO (2004), expõe que a violência nas escolas se manifesta por meio de agressões, roubos e assaltos, estupros, depredações, porte de armas e discriminação racial etc. 


\section{CIÊNCIAS HUMANAS}

REVISTA DO PROGRAMA DE PÓS-GRADUAĞ̈O EM EDUCAĞ̄o

\section{(1) URI|}

Tudo revela o caos que a sociedade atual vem enfrentada. Assim, sendo surge à necessidade de políticas públicas que atuem na raiz do problema.

Madalena Freire (2008) enxerga a educação como uma possibilidade de humanização da sociedade, e isso é possível sim, quando há a soma de esforços e sacrifícios em prol de uma educação mais prazerosa e afetuosa. Como diz o pensador Gonçalves (2004) é necessário que haja esforço, sacrifício para alcançar resultados.Já se sabe que a aprendizagem se dá na troca com o meio e com os outros.E, que dentro do construtivismo o lugar do professor é de mediador, e ele não deve assumir o papel de autoritário, e sim o de democrático e de provocador de saberes.

A educação não é apenas um veículo, que traz a disciplina e as teorias cientificas, como aqui já foi citado, ela contempla também o educar a realidade, onde devem ser supridas as necessidades sociais, afetivas e cognitivas do sujeito.

Aprender significantemente consiste na mudança e ensinar significa instrumentalizar a mudança, e se falando de educação humanizadora tanto o ensinar como o aprender são degraus importantes nessa construção. Ao chegar aos estudos de Milani (2000), no qual traz uma importante abordagem sobre a Cultura de Paz, um elemento chave dentro da educacao humanizada. Isso significa que a educação escolar tem esse desafio propiciar, principalmente em meio a tantos conflitos internos e externos, que são comuns dentro do espaço escolar a paz.

Ao falar de educação humanizadora é necessário acrescentar a questão da segurança física e moral de nossos alunos e professores e dos demais envolvidos dentro do processo de ensino e aprendizagem. Nesse sentido Guimarães (2004), diz que a educação precisa possibilitar a paz. Porque se existe um ambiente saudável, tranquilo e seguro a criança terá maiores probabilidades de se desenvolver e de se constituir como pessoa e como ser humano.

Vivemos em um mundo conturbado e agitado, e isso tem sido tão automático, que não percebemos os conflitos internos e externos, que nos cercam, mas para uma aprendizagem humanizadora Jares (2002), explica que é preciso adotar a chamada educação para paz sistematizada ou também chamada de paz positiva. Hoje, isso é vital para uma melhor atuação do professor e do desenvolvimento cognitivo e intelectual 


\section{CIÊNCIAS HUMANAS}

REVISTA DO PROGRAMA DE PÓS-GRADUAĞ̈O EM EDUCAĞ̄o

\section{(1) URI|}

desse sujeito, já que os índices de violência tem sido tão assustadores dentro dos espaços escolares. Como confirma Barros (2007) ao falar que a violência está estampada nas ruas das cidades, a violência doméstica, os latrocínios, os contrabandos, os crimes de colarinho branco têm levado jovens a perder a credibilidade, quanto ao valor da educação e na construção de uma sociedade mais justa e igualitária, tornando nossos jovens e adolescentes desacreditados e violentos, conforme tem sido visto pelos grandes veículos da mídia.

A paz, a afetividade, a paciência são elementos significativos, quando se pretende desenvolver uma educação de fato humanizadora. Sendo assim, Matos (2006) ainda acrescenta que deve haver uma maior tolerância, o acolhimento caloroso para que esse sujeito se sinta confortável e seguro, a apostar na educação dialógica, priorizar também os aspectos éticos- afetivos. Resumindo, isso significa que a educação humanizadora não acontece de forma instantânea, é sim um processo árduo de importantes construções, que são permanentes e diárias e que cabe professores, órgãos competentes, sociedades e famílias aderirem essa nova abordagem.

A educação é um processo transformador como confirma Freire (2005), ela é capaz de formar sujeitos críticos, capazes de promover transformações sociais, a partir do conhecimento que é adquirido dentro da instituição escolar. Isso que dizer, que não é possível mudar toda uma realidade em meio a tantos conflitos, mas há possibilidade de articular ações que venha amenizar os entraves presente na educação atual e na sociedade como um todo.Nesse sentido Madalena Freire (2008) afirma que o homem é a mais das importantes matéria-prima a ser forjada, lapidada e isso ocorre dentro do processo de escolarização.Dessa forma é possível sim,termos um mundo mais harmônico e igualitário em meio a tantas diferenças e desigualdade que temos.Desde que, cada um seja um agente transformador da sua própria realidade.

Conforme os estudos de Madalena Freire (2008), o homem busca sempre por respostas, enfrentando dificuldades, atravessando crises. E isso representa bem o processo educativo, que no seu percurso passa por todos esses momentos, e cabe a esse educador triblar sabiamente todas essas situações problemas, que afeta diretamente na qualidade e no bom desempenho do processo de ensino aprendizagem. Nesse sentido é 


\section{CIÊNCIAS HUMANAS}

REVISTA DO PROGRAMA DE PÓS-GRADUAĞ̈O EM EDUCAĞ̄o

\section{(1) URI|}

preciso que haja educadores criativos e proativos que consigam em meio a tantos problemas vencer esses obstáculos.

Assim, Pacheco (2008) diz que a educação humanizada é aquela que, incentiva a autoformação cooperativa, compartilha as experiências vivenciadas com dinamismo, o autor ainda aponta que para isso é preciso um elemento chave chamado de professores compromissados.E, essa tem sido também uma grande dificuldade na construção de uma aprendizagem mais humanizadora, pois existe ainda muita negligência dentro da educação por parte de muitos profissionais que não querem assumir esse importante perfil de educadores humanizadores e maior compromissados com arte do educar.

\section{CONSIDERAÇÕES FINAIS}

A partir dessa experiência e da necessidade de uma educação mais e mais humanizadora, aqui relatada foi possível ampliar a nossa visão de mundo, de como a escola deve atuar frente aos conhecimentos, valores, princípios e comportamentos.Porque foi provado mais uma vez aqui, que a educação tem uma função transformadora e moldadora de toda uma sociedade.Percebeu-se ainda que a prática educativa, é uma realidade que é construída, com base nisso é possível sim, mudar a postura e o comportamento dos seres humanos.

É evidente que todos as situações problemas da educação não se resolverão do dia para noite com simples discursos voltados para a humanização do sujeito,é preciso ações concretas que mobilizem toda a sociedade e consolidem em uma educação apalpável e humanista.Sendo assim não se trata de um otimismo ingênuo, mas sim de uma nova forma de pensar e enxergar a educação como fator prioritário e acreditar na sua capacidade de transformação do homem e de todo a uma sociedade.

Fazendo uma linha do tempo, dentro do contexto histórico educacional brasileiro, percebe-se que houve avanços, no que se refere às questões humanas, pois em outrora não havia esse olhar humanista para educação, onde era apenas um lugar para a transmissão de informações, sem se preocupar com as questões afetivas e emocionais do sujeito. 


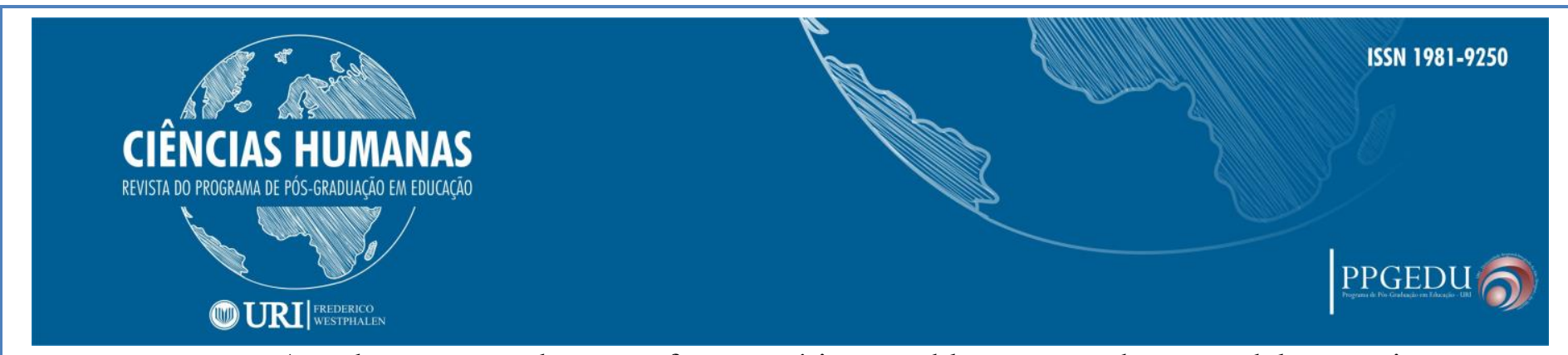

A educação moderna enfrenta vários problemas, sendo um deles aqui apresentado como o processo de desumanização do sujeito como aqui foi discutido. E, isso é algo muito preocupante, sendo necessárias ações e intervenções, que venha de encontro a raiz desse problema. Com o intuito de resgatar a humanização do sujeito, que aos poucos vem se perdendo ao longo dos anos.

É fundamental repensar na educação, não só na questão de conhecimentos científicos, mas prioriza-se a humanização desse sujeito. Reconhecendo que todo esse trabalho é muito sério e complexo, exigindo garra e muita objetividade para se alcançar resultados mais significativos. Nesse sentido percebe que ser um educador humanista e humanizador é algo sempre desafiador, porém hoje é mais do que necessário, principalmente quando os resultados são nítidos, tornando o processo educacional cada vez mais gratificante e prazeroso.

A intervenção na educação contemporânea é necessária, principalmente o toque de humanização, que vem dentro da ação docente como um importante recurso, onde se tem percebido que o processo educativo tem sido construído de uma forma tão fria e sem a afetividade que lhe é necessária. Educar pela ótica da humanização significa olhar o mundo escolar sob outro olhar. Nesse caso a ótica do amor, do carinho e do afeto.Porque a educação como um todo se resume a isso um ato de amor e sacrifícios.

Com tudo que foi exposto a palavra chave é intervenção humanista em busca da superação de um ensino humanizador, e isso se dá por meio do saber e do fazer docente. Todas essas carências precisam ser trabalhadas e intervidas para que tenhamos no presente e num futuro, bem próximo uma educação muito mais significativa especificas. A educação deve ser sempre um espaço para superação e conquistas. Mudar a nossa postura frente aos problemas educacionais se faz necessário, bem como a construção de uma visão sempre otimista,pois o otimismo educacional é o alimento necessário para dar continuidade ao processo educacional, e se tratando do ensino humanista principalmente.

Neste sentido, não é uma ação isolada, que fará o diferencial de uma educação humanizadora, e sim um conjunto de ações, que vai desde os órgãos competentes até a uma equipe multifuncional de educadores e profissionais de cada área específica, que 


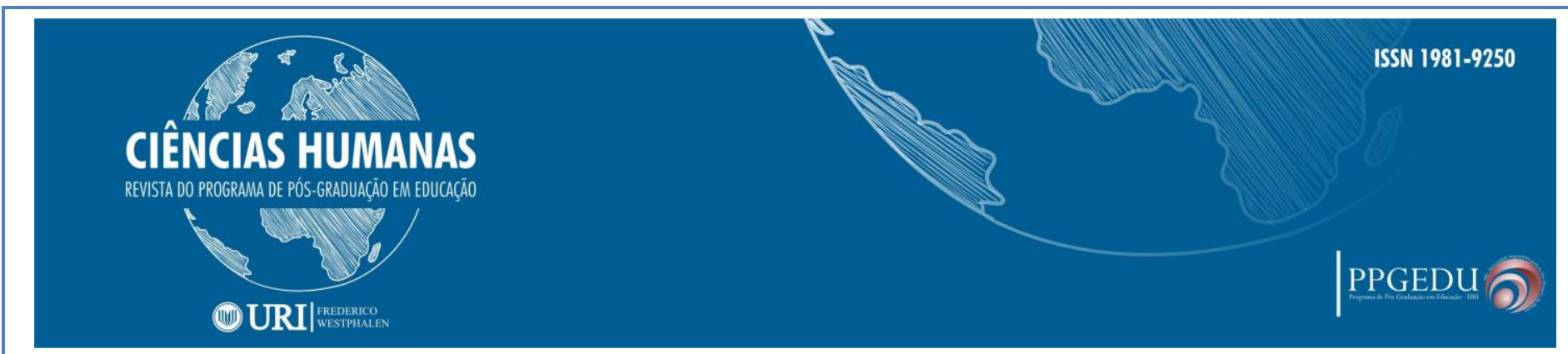

está frente de cada dificuldade, buscando sempre o êxito e uma aprendizagem de fato significativos para todos.

Por último, em resposta ao objetivo inicial e a situação problema aqui proposta, conclui-se que o objetivo foi atingido, pois a partir dessa discussão foi possível, refletir sobre a relevância de uma educação humanizada como contribuidora, para uma educação mais integradora sobre a temática, bem como desconstruindo a visão preconceituosa, de que não é possível construir uma educação mais afetiva e mais humana. Como sugestão, indica-se que novos estudos, sejam realizados dentro dessa importante temática, para que sejam aprofundados outros aspectos, que estão contextualizados com a temática.

\section{REFERÊNCIAS BIBLIOGRÁFICAS}

AURÉLIO, O minidicionário da língua portuguesa. $4^{\circ}$ edição revista e ampliada do minidicionário da língua portuguesa Aurélio. $7^{\circ}$ impressão. Rio de janeiro 2002.

ARROYO, G. Miguel. Ofício de mestre: Imagens e autoimagens. Petrópolis: Vozes, 2000.

BARROS, Jussara de. "Escola X Violência"; Brasil Escola. Disponível em <https://brasilescola.uol.com.br/educacao/escola-X-violencia.htm>. Acesso em 09 de maio de 2017.

BARLACH, L, Limongi-França, A. C., \& MALVEZZI, S. O conceito de resiliência aplicado ao trabalho nas organizações. Revista Interamericana de Psicologia, 42,101112. . (2008).

BELON, Antonio Rodrigues; FERREIRA, Bianca Estevam Veloso. Entre os segredos das leituras e a escrita pública. Revista Eletrônica Literatura e Autoritarismo, Santa Maria, n. 20, jul.-dez. 2012. Disponível em:

www.<http://w3.ufsm.br/grpesqla/revista/num20/.> Acesso em: 20 abr. 2017.

BUZAN, B.. The Logic of Anarchy: Neorealism to Structural Realism. New York: Columbia University Press, 2005.

BRASIL. Secretaria de Educação Fundamental. Parâmetros curriculares nacionais: introdução aos parâmetros curriculares nacionais/ Secretaria de Educação fundamental. Brasília: MEC/SEF, 1997. p 107-108. 


\section{CIÊNCIAS HUMANAS}

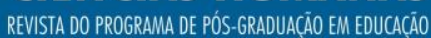

\section{(1) URI|}

CASTANHO, Maria Eugênia. Universidade à Noite: fim ou começo da jornada?. Campinas: Papirus, p. 21-29,1989.

CORTELLA, M. S. A Escola e o Conhecimento: fundamentos epistemológicos e políticos. São Paulo: Cortez: Instituto Paulo Freire, 4a edição, p. 129-159, 2001.

CIMBALISTA, S. Condições de trabalho, tecnologia e resiliência no contex to do sistema de produção flexível. Análise Conjuntural, 29(9-10), 12-14. (2007).

CURY, Agusto. Pais brilhantes professores fascinantes: educação auto-ajuda, São Paulo: Sextante, 2007.

COMENIUS, Jan Amos. Didática Magna. São Paulo: Martins Fontes, 2002.

CHIZZOTTI, Antonio. Pesquisa qualitativa em ciências humanas e sociais. 3. ed. Petrópolis, RJ: Vozes, 144p. 2010,

DARWIN, C. R. A origem das espécies. São Paulo: Itatiaia, 1985.

FERNANDÉZ, Alicia. A inteligência aprisionada. Porto Alegre: Artes Médicas,1991.

FERNANDÉZ, Alícia. O Saber em Jogo: a psicopedagogia propiciando autorias de pensamento. RS: Editora Penso, 2001.

FREEDMAN, R. Drug therapy: schizophrenia. ENGL J Med; 349:1738-1749. (Discussão do uso clínico de muitos dos fármacos prescritos para o tratamento da esquizofrenia, inclusive agentes atípicos.). 2003.

FREIRE, Paulo. Pedagogia do oprimido. 42 ${ }^{\mathrm{a}}$ ed. Rio de Janeiro, 2005 a.

FREIRE, Paulo. Conscientização: teoria e prática da libertação. $3^{\mathrm{a}}$ ed. São Paulo: Centauro, 2005b.

FREIRE, Paulo.Pedagogia da autonomia: saberes necessários à prática educativa. $31^{\mathrm{a}}$ ed. São Paulo: Paz e Terra, 2005c.

FREIRE, Madalena. Educador,a dor educa. São Paulo. Paz e Terra, 2008.

NIETZSCHE, Friedrich, Escritos sobre Educação (Tradução de Noéli Correia de Melo sobrinho);Rio de Janeiro- São Paulo: Editoras Loyola e Editora PUC-RIO, 2003.

GUIMARÃES, Viviane. A. O amor e a educação no sistema: e a educação no sistema preventivo de Bom Bosco. Revista Eletrônica de Educação. Ano I, No. 02, jan./jul, 2008 . 


\section{OCURI|}

GONÇALVES, Patrícia. Postura Proativa: a atitude dos profissionais de alta performance. Disponível em: http://www.hdibrasil.com.br/publicacoes/newsletterservice- news/689-postura-proativa-a-atitude-dos-profissionais-de-alta- performance. Acesso em: 30/05/2018.

GOLEMAN, D. Como lidar com emoções destrutivas: para viver em paz com você e com os outros: diálogo com a contribuição do Dalai Lama. Rio de Janeiro: Campus: Elsevier, 2003.

HALDANE, J. B. S. The causes of evolution. London: Longmans, 1932.

HAUSER, M. D. The evolution of communication. Cambridge: The MIT Press, 1996.

ISQUERRA, J. e Pérez, N. (2007). ). Habilidades emocionais Educação XXI, 10, 61-82. Rieffe, C., Villanueva L., Adrián, J. E. e Gómz, A. B. Queixas somáticas, humor e consciência emocional em adolescentes. Psicothema. (2009).

INEP. SAEB : Novas Perspectivas. Instituto Nacional de Estudos e Pesquisas Educacionais.A Evasao Escolar. Brasília: O Instituto, 2016.

JARES, Xejus. Educação para a paz: sua teoria e sua prática. $2^{a}$ ed. Porto Alegre: Artmed, 2002.

JUNG, Carl Gustav. A natureza da psique. Tradução de Pe. Dom Mateus Ramalho Rocha, Petrópolis/RJ: Vozes, 1991.

LAKATOS, Eva Maria. Fundamentos de metodologia científica. 5.ed. São Paulo: Atlas, 2007.

MANGINI, Rosana C. R. Privação afetiva e social: implicações nas escolas. In: MEDEIROS, R. (Org.). A escola no singular e no plural: um estudo sobre violência e drogas nas escolas. Belo Horizonte: Autêntica, 2008.

MARTINS, Heloisa Helena T. de Souza. Metodologia qualitativa de pesquisa. Educação e Pesquisa, São Paulo, v.30, n.2, p. 289-300, maio/ago. 2004.

MARTÍNEZ, L. A abordagem de questões sociocientíficas na formação continuada de professores de ciências: contribuições e dificuldades. Bauru, 2010. Tese (Doutorado) Faculdade de Ciências da Universidade Estadual Paulista. Enseñanza constructivista sobre conceptos de cinética en la formación inicialde profesores de química. Educación Química. [S.1.], v. 20, n.3, p.383-92, 2009.

MALDONATO, Mauro.A mente plural.Biologia,evolução,cultura.Trad.de Roberta Barni.São Paulo:Unimarco Editora,2006 


\section{CIÊNCIAS HUMANAS}

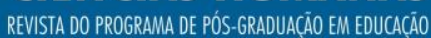

\section{(1) URI|}

MATOS, Kelma Socorro Lopes. Jovens e Crianças: outras imagens. Fortaleza: Editora UFC, . p.56- 61. 2006.

MILANI, Faizi. “Cidadania: construir a paz ou aceitar a violência?”. Mogi Mirim: Planeta Paz, 2000.

OLIVEIRA, M. A. Resiliência: análise das Publicações no Período de 2000 a2006. Psicologia: Ciência e Profissão, 28(4) 754-767. (2008).

PACHECO, José. Escola da Ponte: formação e transformação da Educação. Petrópolis, RJ: Vozes, 2008.

SILVA, Pedro. N. Ética, indisciplina e violência nas escolas. Petrópolis, RJ: Vozes, 2004.

PEREIRA, Helena Bonito Couto. Narrativas brasileiras no século XXI - tradição e renovação. s.d. Disponível em: <http://www.brasa.org/Documents/BRASA_XI/HelenaPereira.pdf $>$. Acesso em: 15 jul. 2018.

RAMACHANDRAN, V. S. O que o cérebro tem para contar: desvendando os mistérios da natureza humana. Rio de Janeiro: Zahar, 2014.

SAVIANI, Dermeval. Escola e Democracia: teorias da educação, curvatura da vara, onze teses sobre educação e política. 33. ${ }^{a}$ ed. revisada. Campinas: Autores Associados, 2000 .

SOUZA, M. T. S., \& CERVENY, C. M. O. (2006). Resiliência psicológica: revisão da literatura e análise da produção científica. Revista Interamericana de Psicologia, 40(1), $119-126$.

STERNBERG, R. J. Psicologia cognitiva. Porto Alegre: Artmed. (2000).

UNESCO. Declaração Mundial sobre Educação para Todos: satisfação das necessidades básicas de aprendizagem. 1990. Disponível em <http://unesdoc.unesco.org/images/0008/000862/086291por.pdf>. Acesso em 20/6/2018.

UNESCO. Políticas públicas de/para/com juventudes. Brasília: UNESCO, 2004

VIGOTSKI, L. S. Psicologia da arte. São Paulo: Martins Fontes. 2001.

WILKINSON, G. Food sharing in vampire bats. Scientific American, 262, 2, p. 64-70, 1990. 